\title{
Theory of attractive quality and the Kano methodology - the past, the present, and the future
}

Lars Witell, Martin Lofgren and Jens Jörn Dahlgaard

\section{Linköping University Post Print}

\section{Tweet}

N.B.: When citing this work, cite the original article.

This is an electronic version of an article published in:

Lars Witell, Martin Lofgren and Jens Jörn Dahlgaard, Theory of attractive quality and the Kano methodology - the past, the present, and the future, 2013, Total Quality Management and Business Excellence, (24), 11-12, 1241-1252.

Total Quality Management and Business Excellence is available online at informaworldTM: http://dx.doi.org/10.1080/14783363.2013.791117

Copyright: Taylor \& Francis (Routledge): SSH Titles http://www.routledge.com/

Postprint available at: Linköping University Electronic Press http://urn.kb.se/resolve?urn=urn:nbn:se:liu:diva-101379 
Theory of Attractive Quality and the Kano Methodology - The Past, the

Present, and the Future

\author{
Lars Witell \\ CTF, Service research center \\ Karlstad University \\ Karlstad, Sweden \\ Lars.Witell@kau.se \\ and \\ Business Administration \\ Linköping University \\ Linköping, Sweden \\ Lars.witell@liu.se
}

Martin Löfgren

CTF, Service research center

Karlstad University

Karlstad, Sweden

Martin.Lofgren@kau.se

Jens J. Dahlgaard

Division of Quality Technology and Management

Linköping University

Linköping, Sweden

Jens.jorn.dahlgaard@liu.se 


\begin{abstract}
The theory of attractive quality and the Kano methodology were introduced about 30 years ago. Since then, research and practitioner communities have adopted both the theory and the methodology as they help to explain the roles different quality attributes play for customers. This paper reviews 147 research papers published between 1984 and 2012 and identifies three distinct phases in the development of the research field; Emergence, Exploration, and Explosion. In addition to the review of existing literature, the present paper sets the scene for the next phase of the research - Explanation - to further develop the field.
\end{abstract}

Keywords: Theory of attractive quality, Kano methodology, customer needs, customer satisfaction. 


\section{INTRODUCTION}

The customer's role in understanding what quality really is, and the question of how to develop and deliver attractive products and services of a high quality, are at the heart of quality management (Deming, 1986; Juran, 1992; Dahlgaard et al. 2002, 2008). Building on Herzberg et al.'s (1959) motivation theory, Kano et al. (1984) introduced the theory of attractive quality to better explain the roles that different quality attributes play for customers. One key feature of the theory of attractive quality is that it includes a methodology that enables companies to classify and understand the effects of different quality attributes. The close link between the theory of attractive quality and a method to put the theory into practice - the Kano methodology - makes it essential to understand quality on an attribute level from the customer's perspective.

Since its introduction into academia, the theory of attractive quality has been subject to increasing interest, and the Kano methodology has been applied in many companies as a method for understanding customer needs. In practice, managers have experienced inconsistencies and problems when new methods suggested by researchers have failed to provide similar results to those of previous methods (Witell and Löfgren, 2007). For example, there are several alternatives in terms of wording, evaluation tables and classification methods, and some confusion for managers regarding which alternatives to choose in a development project. The question for the research community is how researchers can support managers with knowledge on the theory of attractive quality, and help them to understand and use the Kano methodology in the right way.

There have been several attempts to synthesize extant research on the theory of attractive quality. Berger et al. (1993), for example, devoted a special issue to the theory of attractive quality in The Center for Quality Management Journal. This was followed by a literature review in Quality Management Journal by Löfgren and Witell (2008), in which the 
authors analyzed the first 20 years' publications on Kano's theory of attractive quality. Recently, Witell et al. (2011) edited a special issue on the theory of attractive quality in The TQM Journal to try to stimulate more research on the theoretical development of the Kano methodology. However, there has been a significant increase in the number of publications on the Kano methodology recently, and the theoretical developments have mainly been published in Total Quality Management and Business Excellence. So, the question arises of what our present level of knowledge about the theory of attractive quality actually is, and what kinds of contributions are now needed to further develop this important research field.

The present paper aims to perform an extensive review of the literature on the theory of attractive quality. The purpose of the paper is to synthesize and critically review the existing research on the theory of attractive quality and the Kano methodology, and investigate the evolution of the research field. The literature review is based on an analysis of 147 research papers published between 1984 and 2012. The next section will present the methodology of the literature review, followed by a presentation of the results in which the research from 1984 to 2012 is described with reference to three phases: Emergence, Exploration, and Explosion. The paper ends by suggesting the next phase, Explanation, and summarizing the characteristics of the three phases. This functions as a stepping stone to the concluding section, in which we discuss how to further develop the research and practice on the theory of attractive quality.

\section{LITERATURE REVIEW}

Our literature review on the theory of attractive quality aims to take stock of, digest, recap, and reduce what is known to a manageable set of key takeaways (MacInnis, 2011). We investigate the breadth of use of the Kano methodology and how different researchers have used and interpreted the theory, and modified the methodology. The literature review and the 
identified research themes provide a synthesis of the theory of attractive quality that serves to integrate and systematically criticize past research (Cooper 1998), and in this way help current and future researchers and practitioners to examine both theory and methodology in detail.

The literature review began with a search for research publications that use the theory of attractive quality, and are held in the following databases: Academic Search Elite, Business Source Premier, Emerald, and SCI Reuters. The search terms used were: Kano, quality, quality dimensions, attractive quality, and customer satisfaction. Papers whose authors could not be identified were rejected, as were papers that were not academic in nature; that is, did not use references, etc. Finally, a 'snowball' technique was employed to investigate the reference lists of the studies collected in order to identify other studies that use the theory of attractive quality or the Kano methodology. A limitation of this literature review is that only papers in English were considered. Therefore, it is possible that this restriction has excluded valuable publications in other languages, especially Japanese. To increase the number of papers from Japan, three conference papers (Kano, 1995; Kano, 2001; Yamada, 1998) were also included. The final selection of papers consisted of 147 publications, of which 124 are empirical investigations and 23 are conceptual extensions of the theory of attractive quality.

Most of these papers have been published in quality management journals, but some can also be found in journals within the service management, marketing, and operations management fields. The most important journal in the development of the research field is Total Quality Management and Business Excellence (25 publications), followed by The TQM Journal (13 publications), and Managing Service Quality (11 publications). It is interesting to note that many of the papers on the theory of attractive quality (with the exception of those in Total Quality Management and Business Excellence, and recently also Managing Service Quality) have been published in journals that are not indexed in SCI Reuters. This means that 
only analyzing SCI-indexed papers would not have provided a complete picture of the research field of attractive quality.

Surprisingly, the majority of the published research has been conducted within service contexts, such as tourism, Internet services, and education. The number of respondents varies from four to 22,518 , and the number of investigated attributes ranges from three to 96 . The theory of attractive quality is often used in combination with other methods for measuring quality or developing new products. Examples of such methods are QFD, SERVQUAL, FMEA, Technology Readiness, and Pugh Concept Selection.

\section{IDENTIFICATION OF PHASES}

The 124 empirical papers on the theory of attractive quality were analyzed and the journal, empirical context, number of respondents and number of investigated attributes were described. Based on the analysis, we identified three phases of the research, across a timespan ranging from 1984 to 2012. The time period, key characteristics, key contributions, research themes and key references for each phase were identified; based on the content of these dimensions, each phase was given a name that summarized the research therein: Emergence (1984-1999), Exploration (2000-2008), and Explosion (2009-2012). These phases will be described below.

\section{EMERGENCE, 1984-1999}

The first phase of research, Emergence, includes 12 papers that were published during the first 15 years in which the research field was established. The contributions emerged in a limited range of journals within the fields of quality management and marketing. In addition to the journal publications, a few conference papers published by professor Kano and his research team (Kano, 1995; Yamada 1998) were important for the emergence of the theory of 
attractive quality. Of the 12 papers, seven included empirical investigations using the Kano methodology, while five were conceptual contributions.

The theory of attractive quality takes its point of departure in the motivator-hygiene theory (M-H theory), suggesting that factors causing job satisfaction differ from those causing job dissatisfaction (Herzberg et al., 1959). Inspired by Herzberg's work, Kano and Takahashi (1979) developed the concept of the M-H property of quality, which Kano et al. (1984) rebranded as "Attractive quality and must-be quality." In relation to this, Kano et al. (1984) are regarded as having established a new research field due to the fact that, in addition to providing a conceptual basis for the theory, they also provided a methodology for its application - the Kano methodology (see Figure 1). Under the Kano methodology, a specific developed questionnaire is used to classify each quality attribute. The classification is made on the basis of if a feature is present (functional form of the question) or not (dysfunctional form of the question). Then, a given evaluation table (the middle part of figure 1) is used to classify each attribute into one of five quality dimensions: (A) attractive quality, $(\mathrm{O})$ onedimensional quality (M) must-be quality, (I) indifferent quality, and (R) reverse quality. The category (Q) 'questionable' in figure 1 contains skeptical answers, and it is debatable whether the respondent has understood the question.

- Insert Figure 1 about here -

An important contribution within this phase of the research was the special issue of The Center for Quality Management Journal (CQM Journal) (Berger et al., 1993). The special issue is an extensive compendium of ideas and experiences of using Kano's theory of attractive quality in practice. One piece of evidence that shows the importance of the special issue is that Professor Kano contacted the CQM Journal and asked for additional copies of the special issue to use in his teaching (Burchill et al., 1994). Even today, many of the ideas and 
conceptualizations in the special issue push the limits and challenge the assumptions of the Kano methodology.

Following the tradition of the CQM Journal's special issue, Lee and Newcomb (1997) introduced new measures and aids to facilitate the classification of quality attributes in a case study from NASA. Lee and Newcomb (1997) also discussed alternative statistical tests and provided guidelines for the use of statistical tests in practice. In addition, Matzler et al. (1996) and Matzler and Hinterhuber (1998) provided an extensive empirical investigation of skies (more than 1500 customers) that contributed to building a strong foundation for the theory of attractive quality.

To summarize, the Emergence phase is built on a few strong academic papers that established the research field. The most important contributions are the theory of attractive quality itself, and the Kano methodology, as well as functional and dysfunctional forms of questions that put the theory into practice. Following this research, a number of new measures and statistics were introduced in order to improve the classification of quality attributes and the interpretation of results.

\section{EXPLORATION, 2000-2008}

During the Exploration phase, which spanned from 2000 to 2008, 45 papers were published. In addition to an increase in the number of publications, the papers appeared in a wider range of journals, including those on quality management, and also service management and operations management. The empirical context for many studies changed from products to services such as education and hotels.

In the early years of the Exploration phase, Professor Kano published an interesting conference paper entitled "Life cycle and creation of attractive quality" at the fourth QMOD conference in Linköping, Sweden (Kano, 2001). In the paper, Kano questionnaires were used to investigate television remote controls that were available on the market in 1983,1989 , and 
1998. From this, it was demonstrated that a remote control was an attractive quality attribute in 1983, a one-dimensional attribute in 1989, and a must-be quality attribute in 1998 (Kano, 2001). Following this line of research, Nilsson-Witell and Fundin (2005) investigated the early stage of the life cycle, considering the fact that new successful attributes are often indifferent before they become attractive. Using knowledge from both of these papers, we now have empirical evidence to support the life cycle of successful quality attributes suggested by Kano et al. (1984). However, there is still a lack of empirical investigations on alternative life cycles for quality attributes, such as for those quality attributes that do not become a success in the market.

During the exploration phase, three research themes dominate: (1) classification of quality attributes, (2) alternative approaches to classification of quality attributes, and (3) the relationship between the Kano methodology and other methods, such as QFD and SERVQUAL.

The first research theme concerns the core of the Kano methodology - classification of quality attributes. A review of the empirical investigations revealed that 17 papers used the five-level Kano questionnaire, in which five answer alternatives are provided for each question; of these, however, only six studies used the textbook approach to designing the questionnaire. Several studies suggested changes or modifications to the questionnaire, the evaluation table or the types of analyses that can be conducted, in order to improve the results of the empirical investigation. The wording of the answer statements from which the respondent could choose was altered in almost all studies. Nilsson-Witell and Fundin (2005) compared an American version (Berger et al., 1993) of the alternatives ('I enjoy it that way,' 'I expect it that way,' 'I am neutral,' 'I can accept it,' 'I dislike it that way') with a Japanese alternative (Kano et al., 1984) ('I like it that way,' 'It must be that way,' 'I am neutral,' 'I can live with it that way,' 'I dislike it that way'). As a result of such changes to the wording, the 
proportion of 'questionables' (meaning classifications that were not clear) decreased, which means that the validity of a study can be improved by choosing the right way of wording the statements.

Regarding the second research theme, 10 of the 27 empirical studies concerned alternative approaches to the classification of quality attributes. As an example, Kano (2001) introduced a three-level questionnaire for this purpose. Emery and Tian (2002) and Zhang and von Dran (2002) used a 'direct question' approach to investigate the expectations of academic staff with respect to student projects, term papers and websites. Jacobs (1999), as well as Martensen and Grönholdt (2001), classified attributes on the basis of 'importance' by using a 'dual-importance grid' in a structural equation modeling approach using PLS. Jacobs (1999) evaluated customer satisfaction with a cable television service, while Martensen and Grönholdt (2001) studied employee satisfaction.

Witell and Löfgren (2007) compared the traditional approach to classification of attributes (Kano et al., 1984) with alternative approaches (Martensen and Grönholdt, 2001; Emery and Tian, 2002). The various approaches were described, analyzed, and discussed on the basis of an empirical study. The study demonstrated that neither the results of the 'dualimportance grid' nor the 'direct-question approach' had any resemblance to the results of using the traditional Kano methodology. In addition, the three-level Kano questionnaire (Kano, 2001) provides systematically different results than the five-level Kano questionnaire (Witell and Löfgren, 2007). The authors conclude that more research on alternative approaches is needed and suggest usage of the five-level Kano questionnaire.

The third research theme builds on Matzler and Hinterhuber's (1998) work and discusses the relationship between the Kano methodology and other methods, such as QFD, SERVQUAL, FMEA, Technology Readiness, and Pugh Concept Selection. The most common 'pair of methods' is the Kano methodology and QFD. As an example, Tan and Shen 
(2000), Shen et al. (2000), and Tan et al. (1999) used the classification of attributes to adjust the importance weights of customer needs in the House of Quality in QFD. The method used by Tan and Pawitra (2001) and Pawitra and Tan (2003) prioritizes 'attractive' quality attributes, whereas the method suggested by Tan and Shen (2000), Shen et al. (2000), and Tan et al. (1999) prioritizes 'must-be' quality attributes.

The contribution of the research in the Exploration phase can be described as an investigation of alternative approaches and the identification of different contexts for using the Kano methodology. The use of alternative wordings, approaches, types of analyses, scales, and so forth was fruitful, since it introduced variation into the approaches towards classification of quality attributes; however, the results of the new approaches and alternatives have often been proven to differ from the traditional Kano methodology. The introduction of alternative methods is a strength as well as a challenge of the Exploration phase, because we still do not know which methodology is the most effective.

EXPLOSION, 2009-2012

Between 2000-2008 an average of five papers per year were published; in 2009 this figure reached an astonishing 20 academic papers, while for 2010, 2011, and 2012 the totals were 21,23 , and 26, respectively. It is therefore apparent that research on the theory of attractive quality entered an Explosion phase in 2009. A possible explanation for the rising number of publications on the theory of attractive quality is that there was also a growth in the number of possible outlets. The African Journal of Business Management, for example, was established in 2007, and this journal is represented with seven publications that were published between 2010 and 2012. In addition to totally new journals, research spread to a range of journals outside the prior domain of quality, management, and service journals in this phase. Examples are Building and Environment and Quality of Life Research Journal. 
At first glance, it seems as though the 90 papers published during the Explosion phase were of basically the same type as those from the preceding phases, Emergence and Exploration. The fact that the new research followed in the trajectories of previous research can be seen by the fact that: (1) services were still the main empirical context, and (2) the combination of the Kano methodology with other methods such as QFD and SERVQUAL was still a very common research approach.

In the Explosion phase the Kano methodology was applied in various new empirical contexts, but research that challenged or questioned the methodological and theoretical foundations of the theory of attractive quality was scarce. However, there were a few exceptions that tried to challenge previous research and break new ground.

In a special issue of The TQM Journal, published in 2011, on the theory of attractive quality, the intention was to discuss and contribute to the further development of the theory of attractive quality. As an example, Högström (2011) revisited the wording of questions, answering alternatives and the evaluation table, and demonstrated the necessity of adapting the Kano methodology to the nature of experiences. The author challenged the traditional evaluation table by investigating the importance rating of different cells in the evaluation table, and suggested a new evaluation table.

Another exception was Gruber et al. (2011), who examined the attributes of effective frontline employees dealing with customer complaints in personal interactions. The research revisited the life cycle of quality attributes in a cross-cultural study, suggesting that the ability and attributes of service employees to delight customers varied from country to country in a systematic manner. In addition, Löfgren et al. (2011) investigated the existence of the life cycle of successful quality attributes and identified three alternative life cycle versions for quality attributes. The research also extended the theory of attractive quality by identifying the reverse movement of certain quality attributes, suggesting that a quality attribute can take 
a step backwards in the life cycle through a change in the design of the product or service in question.

The Explosion phase can be summarized as representing, with a few exceptions, 'more of the same' (compared to the Exploration phase), and does not seem to have reached its end yet. This means that instead of challenging and moving the research on the theory of attractive quality forward, the field has been focused on providing additional empirical studies in new contexts. All of these studies have their individual merits, but the research field in general has come to a standstill during this Explosion phase.

\section{DISCUSSION}

The body of research on the theory of attractive quality has grown from one paper published each year in the Emergence phase, to five papers in the Exploration phase, and now over 20 papers each year in the Explosion phase. This suggests that the field is growing, based on the original ideas presented by Professor Kano and his team. However, this growth also raises concerns regarding how, and in what direction, the quality of the research field is developing.

It seems evident that too much research has simply applied the Kano methodology without discussing its implications for the theory of attractive quality. When introducing new approaches for the classification of quality attributes, much research to date fails to investigate how the new approach differs from existing approaches. In addition, too little research has focused on areas in which knowledge is limited, such as attractive quality creation and life cycles of quality attributes. Consequently, even though we can see a growth in the number of publications on the Kano methodology, there is a need to set a research agenda for the further development of the theory of attractive quality.

One question to ask is whether the research in the Explosion phase really has reached a plateau in terms of quality. Several pieces of empirical evidence suggest that this is the case. 
First, the share of empirical investigations that use statistical tests for classification of quality attributes is stable. Almost all empirical investigations still classify quality attributes based on the statistical mode; in other words, they simply count the number of responses in a certain quality dimension. This means that we cannot be certain that the classification assigned to a specific attribute is correct. Second, if we look at the average sample size in empirical investigations, it has actually increased over the three phases, but when we investigate the median of the sample size, we can actually see a reverse pattern, with shrinking sample sizes. Thus, it seems that we have two different developments in the research field, where one research stream conducts large-scale empirical investigations and another uses small sample sizes. Third, since the number of studies is increasing, new research should avoid previous mistakes. If a study shows that a certain approach of the Kano methodology provides different results to those expected, for instance, forthcoming studies should take the problems with the suggested approach into consideration when designing their study. There is a need to become better at building on previous research so that we can create a common platform from which to further develop the research field on the theory of attractive quality.

\section{Are We Moving towards an Explanatory Research Phase?}

It is necessary to move from what some authors call 'content-free' research to research that makes a substantial contribution to the theory of attractive quality. This means that the standards of the research methodology must be improved, more challenging research questions should be posed, and more extensive empirical investigations of the theory of attractive quality in practice should be conducted. The basic Kano methodology has been widely used and altered. Several alternative approaches have been tested, yielding both good and surprising results. Most approaches provide different results to those given by the original five-level Kano questionnaire; until we know that these approaches provide a more 'correct' 
result, the five-level Kano questionnaire, in combination with self-stated importance and statistical tests, is the state-of-the-art version of the Kano methodology.

Our knowledge about the theoretical foundation of the theory of attractive quality is sparse and has been given very little attention in the 147 papers published. Theoretical issues such as attractive quality creation, life cycles of quality attributes, and customer satisfaction are included in some publications, but more knowledge about the very core of the theory of attractive quality is needed. Based on this lack of knowledge and the results of the present study, an Explanatory research phase could include the following research themes:

The first research theme concerns the theoretical foundation of the theory of attractive quality in customer satisfaction. Although the theory of attractive quality is often discussed in relation to customer satisfaction at an overall level, it was developed to be applied at an attribute level. In this context, Kano et al. (1984, p. 5) made the interesting observation that 'the correlation between the feeling of satisfaction for the product as whole ... is a subject left for future study.' It is apparent that the underlying assumptions of the theory of attractive quality need to be further validated and investigated through empirical studies. In addition, it is important to understand the characteristics of the different quality dimensions and to validate these characteristics with empirical studies.

The second research theme, the very essence of the theory of attractive quality, is concerned with the fact that satisfaction and dissatisfaction are not necessarily opposites. This view has been accepted and adopted in previous research, but not questioned or investigated. This issue is not independent of the first research theme because though satisfaction and dissatisfaction may be opposites on two different product/service attributes, how such opposites influence overall satisfaction depends on the importance of each attribute seen from the consumer's perspective. 
The third research theme concerns the relationship between the quality dimensions, and how they are connected to various experiences and feelings of customers. This can be seen, for example, in the experience of an opera or a rock concert, or in that of using advanced products such as smart phones, where the overall experience of using the product is more important than the experience of the different attributes. In such cases it might be necessary to first measure the overall experiences, and then identify the more detailed experiences related to different quality attributes. In addition, we may have a problem with Kano's methodology when interaction between attributes has profound affects. In relation to experiences and feelings we may have situations where attributes one by one may not have strong effects but combined they may have profound affections. An interesting issue to consider is whether we are approaching the limits of the theory of attractive quality, or if the Kano methodology can be further developed to also deal with experiences. There are two alternative ways in which to approach this issue: either adapt the methodology to experiences (see Högström, 2011), or develop new frameworks for the experience society (see, for instance, the Diamond Model suggested by Dahlgaard et al. (2008)).

The fourth research theme focuses on the life cycle of quality attributes. One of the key theoretical issues of the theory of attractive quality is that quality attributes are dynamic. Successful quality attributes are assumed to follow a life cycle in which a quality attribute starts by being 'indifferent,' then moves to 'attractive,' through to 'one-dimensional,' and, finally, ends up as 'must-be.' However, there is limited empirical evidence to support the suggested life cycle of quality attributes, and the knowledge on alternative life cycles for a product's bundle of quality attributes is even more uncertain. There is basically no knowledge about alternative life cycles, or how many attributes follow these types of life cycles.

The fifth research theme concerns the further development of the Kano methodology. One existing challenge for research on the theory of attractive quality is what methodologies 
are needed for researchers and managers to perform empirical investigations, to interpret the results and to turn the results into action, which means creating new, attractive products. The research initiated by Kano and his team about 30 years ago has now led to more than 10 alternative approaches for classifying quality attributes, and even more if we count the minor adjustments to the original approaches. We need to know why these methodologies are different, and which approaches provide the most reliable and valid results.

\section{CONCLUSIONS}

The review of the theory of attractive quality summarized in this paper suggests that although the research field has gained substantial knowledge on the topic during the past 30 years, much remains to be learned. The establishment of the research field by Professor Kano and his team has inspired many researchers to devote their careers to obtaining a better understanding of the relationship between quality attributes and customer satisfaction (at attribute level and overall level), and how this relationship changes over time. Our synthesis of the research on the theory of attractive quality has identified three phases in the development of the research field: Emergence, Exploration and Explosion. One of the main aims of the present study is to identify the developments in, and patterns of, research on the theory of attractive quality, and to aid researchers in identifying how to proceed to the next phase of research to further develop the field.

Now it is time to respond to what Kano wrote in 1984: 'the correlation between the feeling of satisfaction for the product as whole ... is a subject left for future study.' The 'future' has been here for some time, meaning that it is now necessary to revisit the theoretical foundation of the theory of attractive quality. Previous studies have acknowledged that some quality attributes can enhance customer satisfaction and prevent customer dissatisfaction, whereas other attributes affect only satisfaction or dissatisfaction. The work 
by Herzberg et al. (1959), and later by Kano et al. (1984), has been accepted and adopted, but little has been done in terms of enhancing our knowledge of the theoretical similarities and differences of the concepts of satisfaction and dissatisfaction. 


\section{REFERENCES}

Berger, C., Blauth, R., Boger, D., Bolster, C., Burchill, G., DuMouchel, W., Pouliot, F., Richter, R., Rubinoff, A., Shen, D., Timko, M. and Walden, D. (1993). Kano's methods for understanding customer-defined quality. The Center for Quality of Management Journal, 2(4), 2-36.

Burchill, G., Shen, D., Walls, T. and Walden, D. (1994). An issue relating to Kano's method. The Center for Quality of Management Journal, 3(2), 2-4

Cooper, H. (1998). Synthesizing research. Thousand Oaks, CA: SAGE Publications.

Dahlgaard, J.J., Kristensen, K. and Kanji, G.K. (2002). Fundamentals of Total Quality Management, London: Nelson Thornes.

Dahlgaard, J.J., Schütte, S., Alikalfa, E. and Dahlgaard-Park, S.M. (2008). Kansei/affective engineering design - a methodology for profound affection and attractive quality creation.

The TQM Journal, 20(4), 299-311.

Deming, W.E. (1986). Out of the crisis. Cambridge, MA: MIT Centre for Advanced Engineering Study.

Emery, C.R. and Tian, R.G. (2002). Schoolwork as products, professors as customers: A practical teaching approach in business education. Journal of Education for Business, 78(2), 97-102.

Gruber, T., Abosag, I., Reppel, A. and Szmigin, I. (2011). Analysing the preferred characteristics of frontline employees dealing with customer complaints - A cross-national Kano study. The TQM Journal (Kano Special Issue), 23(2), 128-144.

Herzberg, F., Bernard, M. and Snyderman, B. B. (1959). The motivation to work. New York: Wiley.

Högström, C. (2011). The theory of attractive quality and experience offerings. The TQM Journal, 23(2), 111-127.

Jacobs, R. (1999). Evaluating customer satisfaction with media products and services: An attribute based approach. European Media Management Review (Winter).

Juran, J.M. (1992). Juran on Quality by Design. New York: The Free Press.

Kano, N. (1995). Upsizing the organization by attractive quality creation. Paper presented at 1 st World Congress on Total Quality Management, London. 
Kano, N. (2001). Life cycle and creation of attractive quality. Paper presented at the 4th International QMOD Quality Management and Organisational Development Conference, Linköping University, Sweden.

Kano, N. and Takahashi, F. (1979). Nippon QC Gakkai: 9th Annual Presentation Meeting, 21-26.

Kano, N., Seraku, N., Takahashi, F. and Tsjui, S. (1984). Attractive quality and must-be quality. Hinshitsu 14(2), 147-156.

Lee, M.C. and Newcomb, J.F. (1997). Applying the Kano methodology to meet customer requirements: NASA's microgravity science program. Quality Management Journal, 4(3), 95-110.

Löfgren, M. and Witell, L. (2008). Two decades of using Kano's theory of attractive quality: A literature review. The Quality Management Journal, 15(1), 59-75.

Löfgren, M., Witell, L. and Gustafsson, A. (2011). Theory of attractive quality and life cycles of quality attributes. The TQM Journal, 23(2), 235-246.

Martensen, A. and Grönholdt, L. (2001). Using employee satisfaction measurement to improve people management: An adoption of Kano's quality types. Total Quality Management, 12(7-8), 949-957.

Matzler, K. and Hinterhuber, H. H. (1998). How to make product development projects more successful by integrating Kano's model of customer satisfaction into quality function deployment. Technovation, 18(1), 25-38.

Matzler, K., Hinterhuber, H. H., Bailom, F. and Sauerwein, E. (1996). How to delight your customers. Journal of Product \& Brand Management, 5(2), 6-18.

MacInnis, D.J. (2011). A framework for conceptual contributions in marketing. Journal of Marketing, 75(July), 136-154.

Nilsson-Witell, L. and Fundin, A. (2005). Dynamics of service attributes: A test of Kano's theory of quality. International Journal of Service Industry Management, 16(2), 152-168.

Pawitra, T.A. and Tan, K.C. (2003). Tourist satisfaction in Singapore - A perspective from Indonesian tourists. Managing Service Quality, 13(5), 399-411.

Shen, X.X., Tan, K.C. and Xie, M. (2000). An integrated approach to innovative product development using Kano's model and QFD. European Journal of Innovation Management, 3(2), 91-99.

Tan, K.C., Pawitra, T.A. (2001). Integrating SERVQUAL and Kano's model into QFD for service excellence development. Managing Service Quality, 11(6), 418-430. 
Tan, K.C. and Shen, X.X. (2000). Integrating Kano's model in the planning matrix of quality function deployment. Total Quality Management, 11(8), 1141-1151.

Tan, K.C., Xie, M. and Shen, X.X. (1999). Development of innovative products using Kano's model quality function deployment. International Journal of Innovation Management, 3(3), 271-286.

Witell, L. and Löfgren, M. (2007). Classification of quality attributes. Managing Service Quality, 17(1), 54-73.

Witell, L, Löfgren, M. and Gustafsson, A. (2011). Identifying ideas of attractive quality in the innovation process. The TQM Journal, 23(1), 87-99.

Yamada, S. (1998). Idea generation in attractive quality creation. Second International Congress on Total Quality Management, Belgrade, Yugoslavia, 542-547.

Zhang, P. and von Dran, G. M. (2002). User expectations and rankings of quality factors in different web site domains. International Journal of Electronic Commerce, 6(2), 9-33. 


\section{TABLES AND FIGURES}

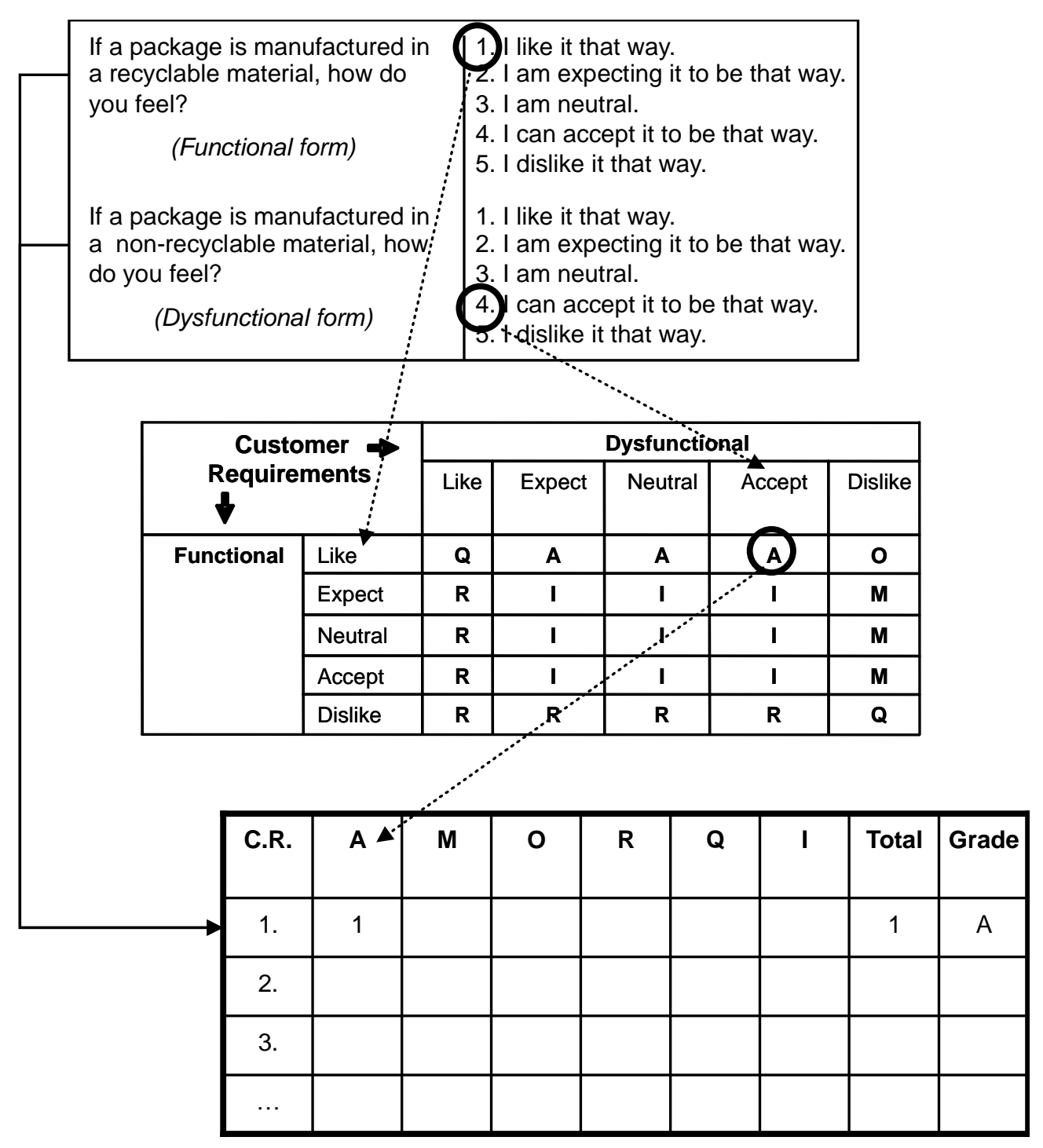

Figure 1: The Kano methodology: looking up questionnaire answers in an evaluation table and tabulating the results. Adopted from Witell and Löfgren (2007). 
Table I: An overview of the literature review.

\begin{tabular}{|c|c|c|c|}
\hline & Emergence & Exploration & Explosion \\
\hline Time period & 1984-1999 & $2000-2008$ & 2009-2012 \\
\hline $\begin{array}{l}\text { Key } \\
\text { characteristics }\end{array}$ & $\begin{array}{l}\text { A few contributions that } \\
\text { established the field of } \\
\text { research. The contributions } \\
\text { emerged in a limited range } \\
\text { of conferences and journals } \\
\text { on quality management and } \\
\text { marketing. }\end{array}$ & $\begin{array}{l}\text { An increase in the } \\
\text { range of journals } \\
\text { publishing research } \\
\text { on the theory of } \\
\text { attractive quality. An } \\
\text { emphasis on journals } \\
\text { on quality } \\
\text { management, but also } \\
\text { service management } \\
\text { and operations } \\
\text { management. }\end{array}$ & $\begin{array}{l}\text { A dramatic increase } \\
\text { in the number of } \\
\text { published papers on } \\
\text { the theory of } \\
\text { attractive quality. } \\
\text { Appearance of } \\
\text { publications in an } \\
\text { even wider range of } \\
\text { journals than before. }\end{array}$ \\
\hline $\begin{array}{l}\text { Key } \\
\text { contributions }\end{array}$ & $\begin{array}{l}\text { Theory of attractive quality } \\
\text { established. } \\
\text { Introduction of the Kano } \\
\text { methodology. } \\
\text { Initial case studies on using } \\
\text { the Kano methodology. }\end{array}$ & $\begin{array}{l}\text { Alternative } \\
\text { approaches to } \\
\text { wording, } \\
\text { classification and } \\
\text { types of attributes. } \\
\text { Kano methodology } \\
\text { used in the context of } \\
\text { product development } \\
\text { and other methods. }\end{array}$ & $\begin{array}{l}\text { Provision of } \\
\text { empirical illustrations } \\
\text { of the Kano } \\
\text { methodology. } \\
\text { Applications of } \\
\text { different approaches } \\
\text { for classification of } \\
\text { quality attributes. } \\
\text { New insights related } \\
\text { to the life cycle of } \\
\text { quality attributes. }\end{array}$ \\
\hline $\begin{array}{l}\text { Research } \\
\text { themes }\end{array}$ & $\begin{array}{l}\text { The theory of attractive } \\
\text { quality. } \\
\text { The five-level Kano } \\
\text { methodology. } \\
\text { Use of statistical methods to } \\
\text { analyze data. } \\
\text { Introduction of new } \\
\text { measures and statistics in } \\
\text { order to improve } \\
\text { classification of attributes } \\
\text { and the interpretation of } \\
\text { results. }\end{array}$ & $\begin{array}{l}\text { Integration of the } \\
\text { Kano methodology } \\
\text { with other methods } \\
\text { such as QFD, } \\
\text { SERVQUAL and } \\
\text { FMEA. } \\
\text { Alternative quality } \\
\text { dimensions and } \\
\text { wording. } \\
\text { Alternative } \\
\text { approaches to the } \\
\text { classification of } \\
\text { quality attributes. }\end{array}$ & $\begin{array}{l}\text { Integration of the } \\
\text { Kano methodology } \\
\text { with other methods } \\
\text { such as QFD, } \\
\text { SERVQUAL and } \\
\text { FMEA. }\end{array}$ \\
\hline Key references & $\begin{array}{l}\text { Kano et al. (1984), } \\
\text { Berger et al. (1993), } \\
\text { Matzler et al. (1996), } \\
\text { Lee and Newcomb (1997). }\end{array}$ & $\begin{array}{l}\text { Martensen and } \\
\text { Grönholdt (2001), } \\
\text { Kano (2001), } \\
\text { Witell and Löfgren } \\
\text { (2007). }\end{array}$ & $\begin{array}{l}\text { Gruber et al. (2011), } \\
\text { Högström (2011). }\end{array}$ \\
\hline
\end{tabular}

